\title{
The Clinical Outcomes of Pharmacist Interventions in Total Parenteral Nutrition services in Riyadh City, Saudi Arabia
}

\author{
Yousef Ahmed Alomi ${ }^{1}{ }^{*}$ D, Aisha Omar Fallatah ${ }^{2}$, Nisreen Al-Shubaar ${ }^{3}$, Abdulaziz Abdullah Qohal ${ }^{4}$, Lila \\ Yahya Alameer ${ }^{5}$ \\ ${ }^{1}$ The Former General Manager of General Administration of Pharmaceutical Care, Former Head, National Clinical \\ Pharmacy and Pharmacy Practice, Former Head, Pharmacy R and D Administration, Ministry of Health, Riyadh, \\ SAUDI ARABIA. \\ ${ }^{2}$ Head, IV Admixture and TPN Services, King Salman Hospital, Ministry of Health, Riyadh, SAUDI ARABIA. \\ ${ }^{3}$ Head, Pharmacy Services, King Salman Hospital, Ministry of Health, Riyadh, SAUDI ARABIA. \\ ${ }^{4}$ Pharmacy Staff, Pharmacy Services, King Salman Hospital, Ministry of Health, Riyadh, SAUDI ARABIA. \\ 5Clinical Pharmacy Staff, General Administration of Pharmaceutical Care, Ministry of Health, Riyadh, SAUDI ARABIA.
}

\begin{abstract}
Objectives: Total parenteral nutrition (TPN) is the perilous component of nutritional care for neonatal, pediatric and adult patients. TPN is designated for someone who cannot or should not consume nutrients through their regular oral pathway. In this study, we explored the clinical outcomes of pharmacist intervention in Parenteral Nutrition at the public hospital in Riyadh city, Saudi Arabia. Methods: In prospective cohort studies, we simulated the data of 12 months of 2015 related to TPN services for neonatal, pediatric and adult patients. Most of the TPN units at hospitals works eight hours per day and seven days per a week. The hospital in Riyadh, Saudi Arabia has 300 beds. The pharmacist intervention consisted of an International Study Model, measure level of activity, rational of clinical intervention, recommendation, and patient with outcome impact. The data were analyzed through Survey Monkey system. Results: The total number of pharmacist interventions were 402 of recognized TPN-related problems. The total number of TPN orders was 394 prescribed to 82 patients. The majority of patients were neonates 303 (75.56\%) followed by Pediatrics 97 (24.19\%). The highest number of critical care interventions were found to be potentially serious 108 (28.8\%) and potentially significant $174(46.4 \%)$. The documented rationale of clinical intervention activities was inappropriate dose $93(24.8 \%)$ drug therapy omission $50(13.3 \%)$ and inappropriate route of administration $41(10.9 \%)$. Most of the patient outcomes were laboratory value improved 170 (45.33\%) and patient condition improved 137 (36.53\%). Conclusion: TPN clinical pharmacist had an essential vital role of preventing a TPN-related problem, improve patient outcome, and avoid the unnecessary supplementary cost. Increasing TPN clinical pharmacist assigned for all TPN services at all health care system in Saudi Arabia.

Key words: Assessment, Clinical outcomes, Interventions, Pharmacist, Total Parenteral Nutrition program
\end{abstract}

Copyright: @ the author(s),publisher and licensee International Journal of Pharmacology and Clinical Sciences. This is an open-access article distributed under the terms of the Creative Commons Attribution Non-Commercial License, which permits unrestricted non-commercial use, distribution, and reproduction in any medium, provided the original work is properly cited.

This is an open access article distributed under the terms of the Creative Commons Attribution-NonCommercial-ShareAlike 4.0 License
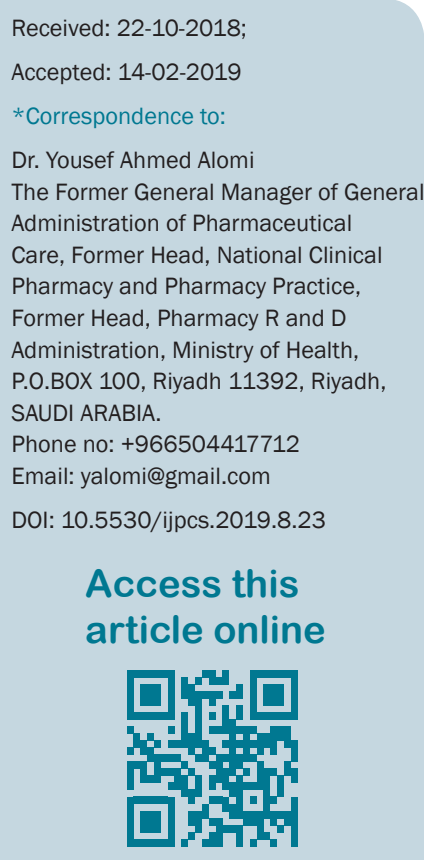

www.ijpcs.net

\section{INTRODUCTION}

Total Parenteral Nutrition (TPN) is the life-threatening part of nutritional care for neonatal, pediatric and adult patients. TPN is specified for somebody who cannot or should not ingest nutrients through their regular oral pathway. Over the past few years, the American Society of Parenteral and Enteral Nutrition (ASPEN) releases several guidelines for the assessment, prescription, 
preparation, administration and follow-up of the TPN with an importance on patient safety. ${ }^{[1]}$ All the major nutrients you need to survive for a while, but sometimes they may progress diseases that make them entirely or partially stop feeding. Some disorders may affect the digestive system or surgery to cut parts of the intestine; the person becomes incapable to supply his body with the food they need. One of the ways to help dazed these conditions is so-called Total Parenteral Nutrition. ${ }^{[1]}$

Total Parenteral Nutrition (TPN) may be defined as an alternative or an additional selection when other options are useless or unsafe. Nutrition Support Professionals (NSP) are dietitians, pharmacists, nurses, and physicians who are specialists in providing and managing enteral and parenteral nutrition in diverse patient populations, from pediatrics to geriatrics. They may work either independently or as part of a nutrition support team. ${ }^{[2-4]}$ The pharmacist plays an excellent role in in this field. The ASPEN published general guidelines to assure patient safety and prevent nutrition-related problems to avoid needless and added economic burden on the healthcare system. The story role of pharmacists started with choosing the best formulation of nutrition support services, preparation of parental nutrition and dispensing of parenteral nutrition. Pharmacists are an integral part of the team because they knows the structures or elements involved in the composition of the intravenous solutions, pharmacodynamics and pharmacokinetics. ${ }^{[5]}$ The pharmacy technician prepares TPN as a sterile parenteral solution under supervision by pharmacists for the compounding of intravenous solutions according to the patient's condition or designs the regimens of TPN. ${ }^{[6]}$

Pharmacists have varied roles in relation to Parenteral Nutrition (PN) therapy including the following: the assessment of patients' nutritional needs; the design, compounding, dispensing, and quality management of PN formulations; monitoring patients' response to PN therapy; supervision of Home Parenteral Nutrition (HPN) programs; education of patients, caregivers, and other health care professionals on nutrition support and conducting PN-related research and class development activities. However, each of these practice fields helps to funding the delivery of safe and effective PN therapy to patients. The clinical pharmacist may be involved in the prescribing of parental nutrition and follow-up with TPN related problems and complications. The pharmacy nutrition program started in mid-1980s with the beginning of clinical pharmacy services in Saudi Arabia. Pharmacist's interventions in patients receiving
TPN orders and revising them before they are prepared and given to the patient contributed to reducing the complication that may follow the false choice of the TPN type, dose and route of administration. Complete follow-up and monitoring patients' response to treatment may limit the values, risks of intravenous solutions and reduce the costs. ${ }^{[7]}$ Several international investigations explored pharmacist interventions in TPN services. The studies reported in Kuwait and was designed to explore pharmacists' role in PN therapy in hospitals of Kuwait. ${ }^{[2]}$ Data were collected via face-toface semi-structured interviews with the senior Total Parenteral Nutrition (TPN) pharmacists at all the hospitals; which provide TPN preparation services (six governmental hospitals and one private hospital). The study focused on comparing pharmacist roles in TPN services, pharmacists educational, training need and how can improvement of pharmacist role in patient care and TPN services. The results did not explain clearly the numbers and numerical ratios of the role of the pharmacist and its intervention in orders and how to correct them, but only by comparing the number of pharmacists and their educational certificates and the number of orders contained in each of the seven centers studied. A prospective study of the interventions in PN was conducted (January-June 2011) the pharmacist intervention with TPN in Spain. ${ }^{[8]}$ The study was conducted for 6 months compared to the current 12-month period. But the number of prescriptions were greater where 1420 prescriptions for PN were documented for 250 patients with 99 interventions were recorded for 65 patients, $35.2 \%$ were made at the beginning of the prescription and 55.3\% of the pharmacist's interventions were made about pediatrics prescriptions corresponding to 33 patients. Based on best of our knowledge; there is no study occurred at Saudi Arabia, the Gulf, or Middle Eastern countries. ${ }^{[9]}$ Therefore, the goal of this study was to explore the impact of the clinical outcome of pharmacist intervention through Total Parenteral nutrients at the public hospital in Riyadh city, Kingdom of Saudi Arabia.

\section{METHODS}

In prospective cohort studies, we simulated the data of 12 months of 2015 related to TPN services for neonatal, pediatric and adult patients. Most of the TPN units at hospitals works eight hours per day and seven days per a week. The hospital in Riyadh, Saudi Arabia has 300 beds. The hospital provides clinical services in different specialties such as adults endocrinology, adults nephrology pediatrics, adults cardiology, adults 
internal medicine, adults surgery, adults critical care, The Neonatal Intensive Care Unit (NICU), The Pediatric Intensive Care Unit, Obstetrics and Gynecology in addition to ambulatory care services and emergency services. Also, the hospital pharmacy offers very comprehensive pharmaceutical services including inpatient pharmacy, ambulatory care pharmacy, Total parenteral nutrition (TPN) services, drug information services, and computerized physician order entry system inpatient and outpatient units.

In 2009, the pharmacy services established TPN services starting from physician's prescription; the pharmacist reviews the order and prepares and dispenses the order; the nurse administers the preparation to the patients. TPN is prepared through sterile USP (797) standards and automated compounding facilities. The cost of TPN in $\mathrm{MOH}$ hospitals calculated by counting the personal cost including the cost of doctor, pharmacist and pharmacy technician per hour and the cost calculation based on preparation time of each TPN bag. Then, the total prices of the overhead cost for the bed and all machines will be used to evaluation the cost of TPN service. Also, the cost of purchased materials and supplies plus non-salary cost. They also considered the purchased prices of TPN lab tests and average length of stay of neonatal, pediatric and adult patients. The pharmacist intervention consisted of an International Study Model, measure level of activity, rational of clinical intervention, recommendation, patient and outcome impact. ${ }^{[10-11]}$ The data were analyzed through Survey Monkey system. The study was conducted according to the ethics guidelines set out in the Declaration of Helsinki and written consent from was obtained from the institution.

\section{RESULTS}

The total number of pharmacist interventions were 402 of identified TPN-related problems. The total number of TPN orders was 394 prescribed to 82 patients. The rate of intervention was 4.9 interventions per patient. Out of 402 patients, 209 (51.99\%) was male, $193(48.01 \%)$ was female. The majority of patients were Saudi $266(66.2 \%)$, while the non-Saudi was $136(33.8 \%)$. The majority of patients were neonates 303 (75.56\%) followed by Pediatrics 97 (24.19\%) (Table 1). Most of the interventions were provided by senior registrar $265(65.9 \%)$ followed by consultant $103(25.6 \%)$. The highest number of critical care interventions were found to be potentially serious 108 (28.8\%) and potentially significant 174 (46.4\%) (Table
$2)$. The documented rationale of clinical intervention activities was inappropriate dose 93 (24.8\%) drug therapy omission $50(13.3 \%)$ and inappropriate route of administration 41 (10.9\%) (Table 3). The majority of the pharmacist's recommendation through intervention were dose changes 125 (33.3\%), followed by initiated drug order $49(13.1 \%)$, route changing $44(11.7 \%)$ and drug added 64 (17.1\%) (Table $4 \mathrm{a}$ and $4 \mathrm{~b}$ ). Most of the patient outcomes were laboratory value improved 170 (45.33\%) and patient condition improved 137 (36.53\%) (Table 5).

\section{DISCUSSION}

In this study, we aimed to explore the clinical outcomes of pharmacist intervention in Parenteral Nutrition at the public hospital in Riyadh city, Saudi Arabia. In the past 5 years, the general administration of pharmaceutical care at the $\mathrm{MOH}$ executed several pharmacy practice programs including total parenteral nutrients for neonates, pediatrics and adults. ${ }^{[12,13]}$ The program was part of pharmacy strategic plan at the Ministry of Health hospital. ${ }^{[14]}$ The program was a part of Pharmacy services operated trained pharmacist. The pharmacist

\begin{tabular}{|c|c|c|}
\hline Age & & \\
\hline Answer Options & $\begin{array}{l}\text { Response } \\
\text { Count }\end{array}$ & $\begin{array}{l}\text { Response } \\
\text { Percent }\end{array}$ \\
\hline $0-30$ days & 303 & $75.6 \%$ \\
\hline 1 month- 6 years & 97 & $24.2 \%$ \\
\hline $6-12$ years & 1 & $0.2 \%$ \\
\hline $12-18$ years & 0 & $0.0 \%$ \\
\hline $18-40$ years & 0 & $0.0 \%$ \\
\hline $40-65$ years & 0 & $0.0 \%$ \\
\hline 65 or older & 0 & $0.0 \%$ \\
\hline \multicolumn{2}{|l|}{ answered question } & 401 \\
\hline skipped question & & 1 \\
\hline \multicolumn{3}{|l|}{ Sex } \\
\hline Answer Options & $\begin{array}{l}\text { Response } \\
\text { Count }\end{array}$ & $\begin{array}{l}\text { Response } \\
\text { Percent }\end{array}$ \\
\hline Female & 193 & $48.0 \%$ \\
\hline Male & 209 & $52.0 \%$ \\
\hline \multicolumn{2}{|l|}{ answered question } & 402 \\
\hline skipped question & & 0 \\
\hline \multicolumn{3}{|l|}{ Nationality } \\
\hline Answer Options & $\begin{array}{l}\text { Response } \\
\text { Count }\end{array}$ & $\begin{array}{l}\text { Response } \\
\text { Percent }\end{array}$ \\
\hline Saudi & 266 & $66.2 \%$ \\
\hline Non-Saudi & 136 & $33.8 \%$ \\
\hline \multicolumn{2}{|l|}{ answered question } & 402 \\
\hline \multicolumn{2}{|l|}{ skipped question } & 0 \\
\hline
\end{tabular}




\begin{tabular}{|c|c|c|}
\hline Answer Options & $\begin{array}{l}\text { Response } \\
\text { Count }\end{array}$ & Response Percent \\
\hline consultant & 103 & $25.6 \%$ \\
\hline senior registrar & 265 & $65.9 \%$ \\
\hline Intern & 15 & $3.7 \%$ \\
\hline Registrar & 0 & $0.0 \%$ \\
\hline Other (please specify) & 19 & $4.7 \%$ \\
\hline answered question & 402 & \\
\hline skipped question & 0 & \\
\hline $\begin{array}{l}\text { The intervention } \\
\text { severity codes }\end{array}$ & $\begin{array}{l}\text { Response } \\
\text { Count }\end{array}$ & Response Percent \\
\hline Answer Options & No & $\%$ \\
\hline Potentially Fatal & 36 & $9.6 \%$ \\
\hline Potentially Serious & 107 & $28.5 \%$ \\
\hline Potentially Significant & 174 & $46.4 \%$ \\
\hline Neutral & 58 & $15.5 \%$ \\
\hline Other & 0 & $0.0 \%$ \\
\hline answered question & 375 & \\
\hline skipped question & 27 & \\
\hline
\end{tabular}

would document all pharmacist's interventions during preparation and dispensing the TPN orders. This study sought to identify the cohort pharmacist intervention for one year. In this, the findings displayed most of the patients were neonates and pediatrics because of most of TPN patients for neonates and pediatrics. The adults TPN not well established during the conducting of the study.

The results of the study showed that the rate in intervention per patient was higher than the previous study because of the newly built TPN services in the current site research. ${ }^{[15]}$ The majority of the patients were Saudi because the hospital treats citizens only. The hospitals have newly added the non-Saudi though health insurance system of the program. Most of the interventions were provided by senior registrar physician because of the profound experiences with TPN or involved under the residency training program. The highest number of critical care interventions were potentially severe or significant because TPN considered as high alert medications by Institute for Safe Medication Practices (ISMP) and may lead to serious complications and death. ${ }^{[16]}$

The documented rationale of clinical intervention activities was inappropriate dose, drug therapy omission and inappropriate route of administration similar to the previous studies. ${ }^{[8,15]}$ Most mistakes of TPN orders, especially if do not have non-trained physicians or very organized and structured with TPN

\begin{tabular}{|c|c|c|}
\hline Answer Options & $\begin{array}{l}\text { Response } \\
\text { Count }\end{array}$ & $\begin{array}{l}\text { Response } \\
\text { Percent }\end{array}$ \\
\hline Pharmacokinetic consult & 0 & $0.0 \%$ \\
\hline Adverse drug reaction & 0 & $0.0 \%$ \\
\hline Therapeutic Duplication & 0 & $0.0 \%$ \\
\hline Alternative Therapy & 0 & $0.0 \%$ \\
\hline Dose Standardization & 0 & $0.0 \%$ \\
\hline Contraindication & 0 & $0.0 \%$ \\
\hline Dosage Calculation & 10 & $2.7 \%$ \\
\hline Inappropriate Dose & 93 & $24.8 \%$ \\
\hline Inappropriate Route & 41 & $10.9 \%$ \\
\hline Inappropriate Schedule & 0 & $0.0 \%$ \\
\hline Non-formulary Med Ordered & 0 & $0.0 \%$ \\
\hline Incompatibility & 39 & $10.4 \%$ \\
\hline Drug-Drug Interaction & 0 & $0.0 \%$ \\
\hline Abnormal Lab Test Result & 0 & $0.0 \%$ \\
\hline Changed Lab Test Ordered & 0 & $0.0 \%$ \\
\hline Drug Therapy Omission & 50 & $13.3 \%$ \\
\hline Failure to Receive Medication & 0 & $0.0 \%$ \\
\hline TPN Consultation & 41 & $10.9 \%$ \\
\hline Other & 101 & $26.9 \%$ \\
\hline answered question & 375 & \\
\hline skipped question & 27 & \\
\hline
\end{tabular}

\begin{tabular}{l|c|c|}
\hline \begin{tabular}{l} 
Table 4a: Pharmacist Recommendation. \\
\hline Answer Options
\end{tabular} No & $\%$ \\
\hline Initiate Drug Order & 49 & $13.1 \%$ \\
\hline Discontinue Drug & 0 & $0.0 \%$ \\
\hline Change Drug & 12 & $3.2 \%$ \\
\hline Change Dose & 125 & $33.3 \%$ \\
\hline Change Duration & 0 & $0.0 \%$ \\
\hline Change Route & 44 & $11.7 \%$ \\
\hline Change Schedule & 0 & $0.0 \%$ \\
\hline Add Lab Test & 0 & $0.0 \%$ \\
\hline Discontinue Lab Test & 1 & $0.3 \%$ \\
\hline Other & 144 & $38.4 \%$ \\
\hline answered question & $\mathbf{3 7 5}$ & \\
\hline skipped question & $\mathbf{2 7}$ & \\
\hline
\end{tabular}

guidelines services. Besides, several errors occurred during the calculation of training TPN osmolarity lead to the inappropriate choice of central or peripheral administration vein. The central vein can tolerate high osmolarity while peripheral vein used with low osmolarity. ${ }^{[15]}$ Thus, the pharmacist approvals would meet the appropriate interventions though change the dose or add new medications or choose the proper route of administration. ${ }^{[15]}$ Most of the patient outcomes were laboratory value and patient condition improved reflected the excellent performance of TPN pharmacist 
Table 4b: Order changed based upon Pharmacists recommendation.

\begin{tabular}{|l|c|c|}
\hline Answer Options & $\begin{array}{l}\text { Response } \\
\text { Count }\end{array}$ & $\begin{array}{l}\text { Response } \\
\text { Percent }\end{array}$ \\
\hline Drug Discontinued & 0 & $0.0 \%$ \\
\hline Drug Changed & 13 & $3.5 \%$ \\
\hline Drug Added & 64 & $17.1 \%$ \\
\hline Dose Changed & 125 & $33.3 \%$ \\
\hline Schedule Changed & 0 & $0.0 \%$ \\
\hline Route Changed & 44 & $11.7 \%$ \\
\hline Duration Changed & 0 & $0.0 \%$ \\
\hline Additional Lab Test Ordered & 0 & $0.0 \%$ \\
\hline Unknown & 7 & $1.9 \%$ \\
\hline Other & 122 & $32.5 \%$ \\
\hline answered question & 375 & \\
\hline skipped question & 27 & \\
\hline
\end{tabular}

\begin{tabular}{|l|c|c|}
\hline \multicolumn{2}{|l|}{ Table 5: Patient outcome. } & No \\
\hline Answer Options & 0 & $0.0 \%$ \\
\hline Therapeutic End Point Reached & 137 & $36.5 \%$ \\
\hline Patient's Condition Improved & 0 & $0.0 \%$ \\
\hline Patient's Condition Worse & 170 & $45.3 \%$ \\
\hline Laboratory Value Improved & 0 & $0.0 \%$ \\
\hline Laboratory Value Worse & 0 & $0.0 \%$ \\
\hline Patient's Mental Status Worse & 68 & $18.1 \%$ \\
\hline Unknown & 0 & $0.0 \%$ \\
\hline Infection Improved & 0 & $0.0 \%$ \\
\hline Infection Worse & 0 & $0.0 \%$ \\
\hline Renal Function Improved & $\mathbf{3 7 5}$ & \\
\hline answered question & $\mathbf{2 7}$ & \\
\hline skipped question & & \\
\hline
\end{tabular}

in the healthcare system. The pharmacist plays a vital role during preparation or dispensing the TPN orders. The pharmacist documentation with TPN services is highly suggested to continue. Annual or every two years of conducting about TPN pharmacist intervention is essential to prevent TPN related problems and recover clinical outcome of the patients in the Kingdom of Saudi Arabia. Continual development of the standards of practice, development of local PN protocols and practice guidelines to support pharmacists and to serve the local needs in different countries, standardization of PN-related practices and services and empowerment of pharmacists to accept a stronger leadership role in this dimension of pharmacy practice are among the potential avenues of improvement in this area of clinical pharmacy practice.

\section{CONCLUSION}

Pharmacists have been energetically contributing in providing PN-related services to patients in different countries. TPN clinical pharmacist had an essential vital role of preventing a TPN-related problem, improve patient outcome, and avoid the unnecessary supplementary cost. Increasing TPN clinical pharmacist assigned for all TPN services at all health care system in Saudi Arabia. The empowerment of pharmacists to accept a stronger leadership role in this measurement of pharmacy practice will improve the quality of care provided to patients getting $\mathrm{PN}$ therapy and improve PN services.

\section{ACKNOWLEDGEMENT}

None.

\section{CONFLICT OF INTEREST}

The authors declare no conflict of interest.

\section{ABBREVIATIONS}

TPN: Total Parenteral nutrition; HPN: Home Parenteral Nutrition; PN: Parenteral Nutrition; ASPEN: American Society of Parenteral Nutrition; NSP: Nutrition support professionals; USP: United State Pharmacopeia; NICU: Neonatal Intensive Care Unit, PICU: Pediatrics Intensive Care Unit; ISMP: Institute for Safe Medication Practices; MOH: Ministry of Health; KSA: Kingdom of Saudi Arabia, MEs: Medication Errors.

\section{ORCID ID}

Yousef Ahmed Alomi (D, https://orcid.org/0000-00031381-628X

\section{REFERENCES}

1. ASPEN. What is Parenteral Nutrition. 2007. Cited 2018 Dec 17. Available from: http://www.nutritioncare.org/about_clinical_nutrition/what_is_ parenteral_nutrition/.

2. Katoue MG, Al-Taweel D. Role of the pharmacist in parenteral nutrition therapy: Challenges and opportunities to implement pharmaceutical care in Kuwait. Pharm Pract. 2016;14(2):680.

3. Howard P. Practical nutritional support: working together to make it happen. Proc Nutr Soc. 2001;60(3):415-8.

4. Tucker A, Ybarra J, Bingham A, Blackmer A, Curtis C, Mattox T, et al. American Society for Parenteral and Enteral Nutrition (A.S.P.E.N.) Standards of Practice for Nutrition Support Pharmacists. Nutr Clin Pract. 2015;30(1):139-46.

5. Greenlaw CW. Pharmacist as team leader for total parenteral nutrition 
therapy. Am J Hosp Pharm. 1979;36(5):648-50.

6. Bozat E, Korubuk G, Onar P, Abbasoglu O. Cost analysis of premixed multichamber bags versus compounded parenteral nutrition: Breakeven point. Hosp Pharm. 2014;49(2):170-6.

7. Koletzko B, Jauch KW, Verwied-Jorky S, Krohn K, Mittal R. Guidelines on Parenteral Nutrition from the German Society for Nutritional Medicine (DGEM)-overview. Ger Med Sci. 2009;7:Doc27.

8. Ferrit M, Cancela B, Martinez N, Madrid A, Puerta E, Garcia C, et al. Pharmaceutical interventions in parenteral nutrition in a tertiary hospital. Eur J Hosp Pharm. 2012;19(2):210.

9. Katoue MG. Role of pharmacists in providing parenteral nutrition support: current insights and future directions. Integr Pharm Res Pract. 2018;7:125-40.

10. Ling JM, Mike LA, Rubin J, Abraham P, Howe A, Patka J, et al. Documentation of pharmacist interventions in the emergency department. Am J Heal Pharm. 2005;62(17):1793-7.
11. Mutnick A, Sterba K, Peroutka J, Sloan N, Beltz E, Sorenson M. Cost savings and avoidance from clinical interventions. Am J Heal Pharm. 1997;54(4):392-6.

12. Alomi YA. National Pharmacy Practice Programs at Ministry of Health in Saudi Arabia. J Pharm Scien. 2015;1(2):17-8.

13. Alomi YA. National total parenteral nutrition program at $\mathrm{MOH}$ in Saudi Arabia. EC Nutr. 2016;3:697-9.

14. Alomi YA, Alghamdi SJ, Alattyh RA. Strategic plan of general administration of pharmaceutical care at ministry of health in Saudi Arabia 2012-2022. J Pharm Scien. 2015;1(13):1-8.

15. Gaspar M, Caja M, Romero I, Royo LM, Tudela V. Pharmaceutical intervention with parenteral nutrition. Farm Hosp. 2009;33(6):296-304.

16. Cohen MR. ISMP medication safety self-assessment for high-alert medications. 2017. Available from: https://www.ismp.org/assessments/ high-alert-medications.

Cite this article as: Alomi YA, Fallatah AO, Al-Shubaar N, Alameer LY. The Clinical Outcomes of Pharmacist Interventions in Total Parenteral Nutrition services in Riyadh City, Saudi Arabia. Int J Pharmacol. Clin. Sci. 2019;8(2):135-40. 